\title{
ADSORPTION OF THE ANIONIC DYE OF CONGO RED FROM AQUEOUS SOLUTION USING A MODIFIED NATURAL ZEOLITE WITH BENZALKONIUM CHLORIDE
}

\author{
D. W. Astuti ${ }^{1,2}$, N. H. Aprilita ${ }^{1}$ and M. Mudasir ${ }^{1, *}$ \\ ${ }^{1}$ Department of Chemistry, Faculty of Mathematics and Natural Sciences, Universitas Gadjah \\ Mada, Yogyakarta, 55281, Indonesia \\ ${ }^{2}$ Department of Medical Laboratory Technology, STIKES Guna Bangsa Yogyakarta, \\ Yogyakarta, 55283, Indonesia \\ *E-mail: mudasir@ugm.ac.id
}

\begin{abstract}
Adsorption of the congo red on surfactant-modified zeolite has been conducted using the batch method. This research was studied to obtain an efficient and good adsorbent for congo red with high adsorption capacity. The influences of solution $\mathrm{pH}$, adsorbent dosage, and contact time were determined. The benzalkonium chloride was used as a cationic surfactant to modify the zeolite surface so that it was suitable for the adsorption of congo red. The adsorption kinetics and adsorption isotherm were also systematically investigated. The result shows that the adsorption of congo red on surfactant-modified zeolite with benzalkonium chloride loading of $300 \%$ of external cation exchange capacity had the highest adsorption capacities for anionic congo red. Modification of the zeolite with benzalkonium chloride can be used as a new alternative method for the removal of the anionic dye of congo red from wastewater.
\end{abstract}

Keywords: Adsorption, Surfactant-modified Zeolite, Benzalkonium Chloride, Congo Red

(C) RASĀYAN. All rights reserved

\section{INTRODUCTION}

Dyes are extensively used in the printing inks, textile, packaging, metal plating, and paper industries to use the dyes extensively ${ }^{1,2}$. Several chemicals, biological and physical methods have been used to eliminate dyes from wastewater. Adsorption technique is a physical method that is the most effective in removing dyes from wastewater ${ }^{1,3-9}$. In wastewater management, the zeolite is generally used as an adsorbent, molecular sieves, ion exchanger, and catalysts ${ }^{1,10}$. Permanent negative charges and cation exchange reactions on natural zeolites allow their high ability to bind cationic pollutants but little or no affinity for anionic binding ${ }^{8,11}$. The most commonly used surface-charge modifying agents for zeolite are

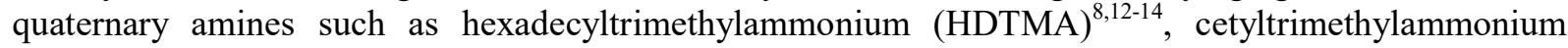
bromide (CTMA), octadecyl trimethylammonium (ODMBA), N-cetyl pyridinium (CPD), sodium dodecylsulphate $(\mathrm{SDS})^{14}$, sodium dodecyl benzene sulfonate (SDBS) ${ }^{14}$, N-cetyl pyridinium bromide $(\mathrm{CPB})^{14}$, benzyl tetradecyl ammonium (BDTDA), stearyldimethylbenzylammonium chloride (SDBAC) ${ }^{15}$, $\mathrm{N}, \mathrm{N}$-dimethyl dehydroabietylamine oxide $(\mathrm{DAAO})^{16}$, and cetyl trimethyl ammonium bromide $(\mathrm{CTAB})^{17,18}$. All of these agents form bilayer structures on the zeolite surface ${ }^{11}$.

Surfactant-modified zeolite for environmental improvement has been learned widely ${ }^{19,20}$. Since the negative charges on their surfaces, the surface of zeolite is often modified by using cationic surfactants to improve the fractional organic carbon content so that it increases the sorption of nonpolar organic contaminants. Cationic surfactants molecule are composed of a hydrophobic tail and a hydrophilic head group $^{11,12}$. Sorption of cationic surfactant can be described by the general model: external surface of zeolite is covered by a surfactant monolayer (hemimicelle) via strong Coulombic interactions at surfactant concentration lower than the critical micelle concentration (CMC) and then at surfactant concentration

Rasayan J. Chem., 13(2), 845-853(2020)

http://dx.doi.org/10.31788/RJC.2020.1325537

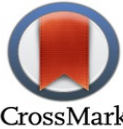


RASĀYAN J. Chem.

Vol. 13 | No. 2 |845 - 853| April - June | 2020

equal to or above CMC, the next layer of surfactant molecules (admicelle) is enclosed to the previous layer via hydrophobic interactions. The formation of this second layer results in a charge inversion of the external surface of zeolite, giving sites where anions may be retained ${ }^{12}$.

So far, the anionic dye removal by modified zeolites using a cationic surfactant, benzalkonium chloride (BC), has been rarely reported ${ }^{21}$. In this study, we report the modification of the zeolite surface with $\mathrm{BC}$ and apply it as the removal adsorbent for the anionic dye of congo red from an aqueous solution. Congo red (CR) is present as an anionic dye in wastewater. Congo red is an azo dye which has two azo bonds ($\mathrm{N}=\mathrm{N}-)$ chromophore in its molecular structure ${ }^{22}$. The research focused on investigating parameters influencing the adsorption capacity, including solution $\mathrm{pH}$, the dosage of adsorbent, and contact time. Freundlich and Langmuir's isotherms examined the experimental adsorption data. Kinetic models of adsorption were also studied to investigate the adsorption rate and controlling mechanisms on the zeolites. The aim of the study helps to know the adsorption properties and potential applications of surfactantmodified zeolites for CR removal from wastewater.

\section{Materials}

\section{EXPERIMENTAL}

The sample of natural zeolite (ZA) was obtained from Klaten, Central Java, Indonesia. This sample contained mordenite in the major component ${ }^{23}$. ZA was washed with de-ionized water to eliminate inorganic impurities. The stock solution of $\mathrm{CR}$ was prepared by diluting the appropriate amounts in deionized water. The cationic surfactant of benzalkonium chloride $(\mathrm{BC})$ was used to modify activated zeolite for suitable removal of CR. The structures of CR and $\mathrm{BC}$ are illustrated in Fig.-1.

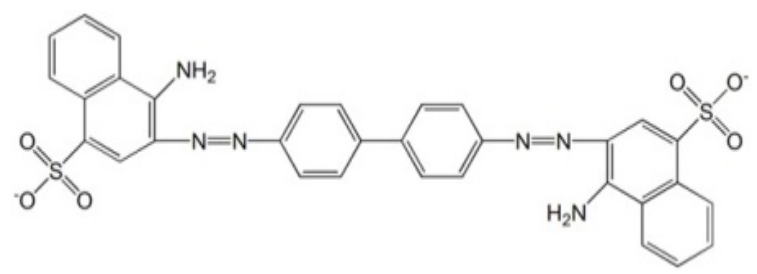

(a)

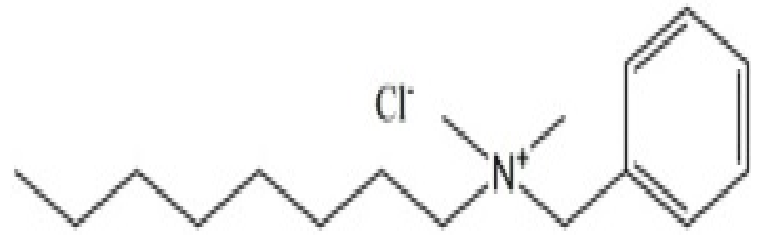

(b)

Fig.-1: Structures of (a) Congo Red and (b)Benzalkonium Chloride

All the reagents used for experimental studies were of analytical grade. All chemical solutions were made by dissolving the stock solutions with de-ionized water.

\section{Surface Modification}

The activation of the natural zeolite was conducted by contacting the adsorbent with an aqueous solution of $\mathrm{NaCl}$. The natural zeolite $(1.0 \mathrm{~g})$ was mixed with $50 \mathrm{~mL}$ of $\mathrm{NaCl} 1 \mathrm{M}$ solution at room temperature. The suspension was agitated in glass flasks using a Memmert shaker. Next, the mixture was filtered and washed with $300 \mathrm{~mL}$ de-ionized water to remove inorganic impurities. The wet activated material was dried at $100{ }^{\circ} \mathrm{C}$ for $24 \mathrm{~h}$ and then used in the modification step. The obtained sample (ZAT) was then washed by de-ionized water and dried in an oven at $105{ }^{\circ} \mathrm{C}$. The cation exchange capacity (CEC) of the ZAT was $99.09 \mathrm{meq} / 100 \mathrm{~g}$, as determined by the ammonium acetate method ${ }^{23}$, while its ECEC was 9.0 meq/100 $\mathrm{g}$ as measured by the method of Ming and Dixon ${ }^{24}$.

The ZAT surface was modified by adsorbing the cationic surfactant of BC. A known quantity of the ZAT $(1.0 \mathrm{~g})$ was prepared with $100 \mathrm{~mL}$ of the $\mathrm{BC}$ aqueous solution at room temperature with the concentration 
RASĀYAN J. Chem.

Vol. 13 | No. 2 |845 - 853| April - June | 2020

equivalents to $100 \%, 200 \%$, and $300 \%$ of its ECEC. The obtained materials denoted respectively as ZATB-1, ZATB-2, ZATB-3, were centrifuged and dried at $60{ }^{\circ} \mathrm{C}^{25}$. The scanning electron microscopy (SEM) (JSM-6510LA) was used to characterize the surface of zeolite after modification using BC. The FTIR spectra of the ZA, ZAT, and ZATB were recorded on a $\mathrm{KBr} 400-4000 \mathrm{~cm}^{-1}$ using a Shimadzu FTIR-8201 PC. The zeta potential of surfactant-modified zeolite was measured by a nanoparticle analyzer SZ-100.

\section{Sorption Tests}

The adsorption was performed by a batch equilibrium technique. The influence of $\mathrm{pH}$ on adsorption was examined by conducting the adsorption of the $\mathrm{CR}$ over a $\mathrm{pH}$ range of 4-10. The initial $\mathrm{pH}$ of the $\mathrm{CR}$ was adjusted by the drop-by-drop addition of $0.1 \mathrm{M} \mathrm{HCl}$ or $0.1 \mathrm{M} \mathrm{NaOH}$. The amount of CR adsorbed at equilibrium, $\mathrm{q}_{\mathrm{e}}\left(\mathrm{mg} \cdot \mathrm{g}^{-1}\right)$, was counted using the mass balance equation given by:

$$
q_{e}=\frac{V\left(C_{o}-C_{e}\right)}{W}
$$

Where, $\mathrm{W}$ is the dosage of zeolite $(\mathrm{g}), \mathrm{V}$ is the volume of the solution $(\mathrm{L}), \mathrm{C}_{\mathrm{o}}$ is the initial concentration of dye $(\mathrm{mg} / \mathrm{L})$ and $\mathrm{C}_{\mathrm{e}}$ is the equilibrium concentration of dye. The effect of the adsorbent dosage was tested by mixing $0.006-0.150 \mathrm{~g}$ ZAT with $20 \mathrm{~mL}$ of $20 \mathrm{mg} \mathrm{L}^{-1} \mathrm{CR}$ solution for $60 \mathrm{~min}$ at optimum $\mathrm{pH}$.

To investigate the mechanism of adsorption, characteristic constants were analyzed using the linearized form of pseudo-first order and pseudo-second-order kinetic models. Kinetic experiments were carried out by agitating $20 \mathrm{~mL}$ of $20 \mathrm{mg} \mathrm{L}^{-1} \mathrm{CR}$ solution with the optimum dosage of adsorbent at room temperature at $120 \mathrm{rpm}$. In this study, samples were drawn out at different time intervals and then centrifuged at 4500 rpm for $10 \mathrm{~min}$, which is sufficient time to reach equilibrium. Dye concentration in the supernatant solution was measured using a Thermo scientific evolution 201 UV Vis Spectrophotometer by measuring absorbance at $\lambda=498 \mathrm{~nm}$. Adsorption isotherms were conducted by contacting the optimum dosage of ZAT with $20 \mathrm{~mL}$ of CR over the concentration ranging from 2 to $30 \mathrm{mg} \mathrm{L}^{-1}$.

\section{Preparation adsorbent}

\section{RESULTS AND DISCUSSION}

Natural zeolite contains the negative charge compensator such as alkaline earth and alkali cations on its surface. Besides that, it also contains undesired components such as metal oxides. By activation using the sodium chloride solution, those contaminants would be removed from the zeolite material. Characterization of functional groups of ZATB-1, ZATB-2, and ZATB-3 was used Fourier Transform Infrared Spectroscopy (FTIR), as shown in Fig.-2.

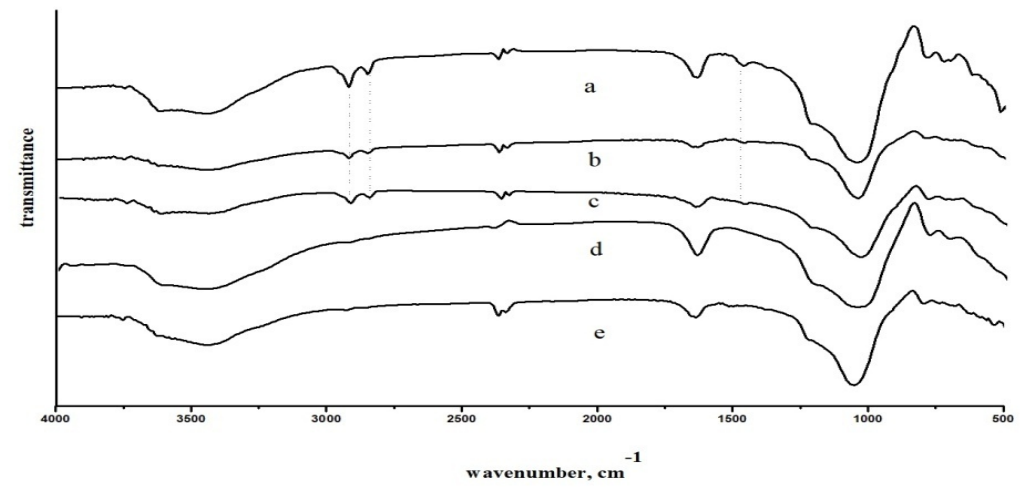

Fig.-2: FTIR Spectra of (a) ZATB-3, (b) ZATB-2, (c)ZATB-1, (d)ZAT and (e)ZA

As shown in the Fig.-2, the peaks at (2924 and 2854) $\mathrm{cm}^{-1}$ are indicative C-H stretching vibration of the hydrocarbon chain. The peak observed at $1465.9 \mathrm{~cm}^{-1}$ is $\mathrm{C}-\mathrm{H}$ bending of the methyl and methylene groups. Three new bands were observed after the modification of zeolite, indicating the presence of $\mathrm{BC}$ 
RASĀYAN J. Chem.

Vol. 13 | No. 2 |845 - 853| April - June | 2020

on the zeolite ${ }^{25-27}$. Due to these vibrations are within the structure of a crystal, the adsorbed BC did not influence the zeolite structure after the modification.

The negatively charged zeolite surface indicates a negligible affinity for anionic compounds, such as the $\mathrm{CR}$ anion. Therefore, the natural zeolite surface needs to be chemically changed such that anionic compounds may be adsorbed. The $\mathrm{BC}$ does not enter the zeolite framework due to the dimensions of the $\mathrm{BC}$ head groups exceed the diameter of the zeolite channel. The quaternary amine ions of $\mathrm{BC}$ can change only the positively charged counter ions $\left(\mathrm{Na}^{+}\right)$at the external surface ${ }^{23,25}$. The SEM micrographs in Fig.-3 evidence some morphological features of the zeolites occurring in the investigated samples.

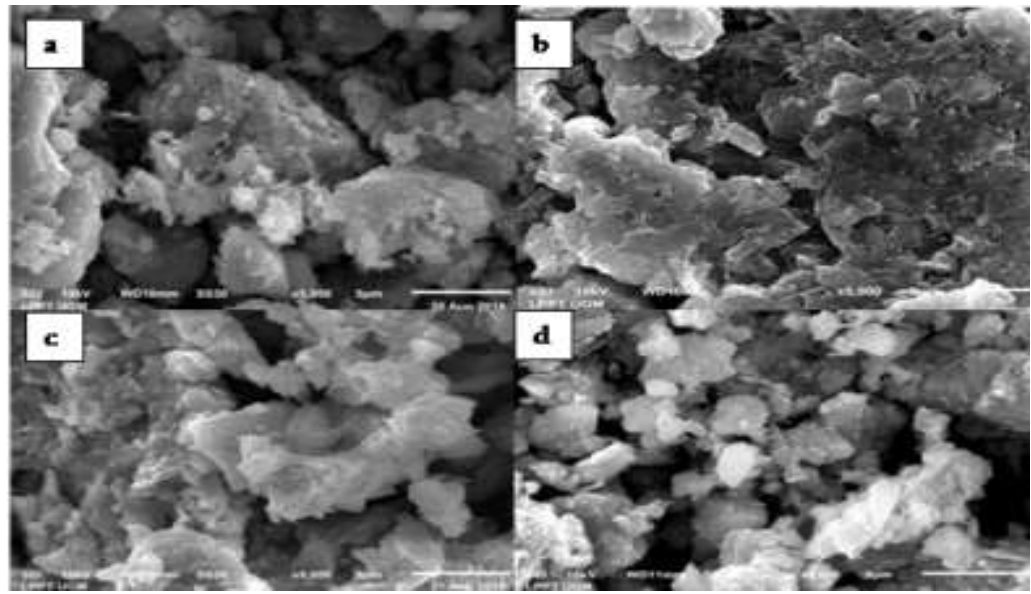

Fig.-3: SEM of the (a)Natural Zeolite, Surfactant-modified Zeolite using BC Aqueous Solution with the Amount Equivalents to $100 \%, 200 \%$, and $300 \%$ of its ECEC (b)(ZATB-1), (c)ZATB-2 and (d) ZATB-3

As shown in the figures the micrographs of natural zeolite (ZA) and surfactant-modified zeolite (ZATB-1, ZATB-2, ZATB-3) expressing some particle aggregation and some features of its irregular surface morphology (Fig.-3a). The crystalline structure of zeolite was indiscernible when its external surface was covered with BC. After the modification step, the organic layer might be formed on the zeolite surface (Fig.-3(b-d)). The dark spots in Fig.-3a indicating pores and open cavities are nearly covered by BC layer. This might be caused by the cationic surfactant adsorbed on the external zeolite surface ${ }^{12}$.

The activated zeolite displays negative charge, which the result of zeta potential of activated zeolite is $38.5 \mathrm{mV}^{28}$. The increasing of the BC loadings on ZAT results in the modify of particles zeta potential from negative to the positive charge. The results of the determination of zeta potentials of the ZATB-1, ZATB-2, and ZATB-3 are 19.3, 25.0, and $33.2 \mathrm{mV}$, respectively. Since a zeta potential is a measure of the potential of an external surface, it can be assumed that $\mathrm{BC}$ cations penetrated in mesopores of zeolite. The zeolites modified with BC at the concentrations above the ECEC clearly show a significant positive charge compared to the unmodified one, probably due to the bilayer formation on the external surface of zeolite $^{29}$. The bilayer on the zeolite surface is produced through hydrophobic interactions. This establishment of a positive charge gives the zeolite anionic exchange capabilities for the anions adsorption such as CR dye ${ }^{18}$.

\section{Influence of Solution pH on CR Adsorption}

The solution $\mathrm{pH}$ is one of the important parameters controlling adsorption processes ${ }^{30}$. It also changes the surface charge of the adsorbent, the ionization extent of different contaminants, as well as the molecular structure of the dy $\mathrm{e}^{31}$. The adsorption used the surfactant-modified zeolite $0.01 \mathrm{~g}$, with the initial $\mathrm{CR}$ concentration of $20 \mathrm{mg} / \mathrm{L}$. The adsorption of anionic dye $\mathrm{CR}$ was conducted in a 4-10 pH range at room temperature. The amount of $\mathrm{CR}$ dye adsorption at various $\mathrm{pH}$ was presented in Fig.-4.

As shown in the figures, the adsorbed amounts of CR on ZATB reached their maximum values when the solution $\mathrm{pH}$ was between 6 and 7. This may be due to interactions of ZATB with CR are more dominant 
RASĀYAN J. Chem.

Vol. 13 | No. 2 |845- 853| April - June | 2020

than with the $\mathrm{OH}^{-}$ions. At a very low solution $\mathrm{pH}$, the positive charge on the solution interface will increase and the zeolite surface will appear positively charged. However, CR in the solution tends to be a neutral species due to protonation. This situation results in a decrease in anionic dye adsorption ${ }^{32}$. On the contrary, at high $\mathrm{pH}$, the positive charge on the solution interface will decrease and $\mathrm{CR}$ will be in negatively charged species, together with $\mathrm{OH}^{-}$ion. Therefore, there will be a competitive interaction of positively charged ZATB with either the negatively charged $\mathrm{CR}$ dye or with $\mathrm{OH}^{-}$ions. As a result, the $\mathrm{CR}$ adsorption will again decrease at $\mathrm{pH}>7^{31,33}$.

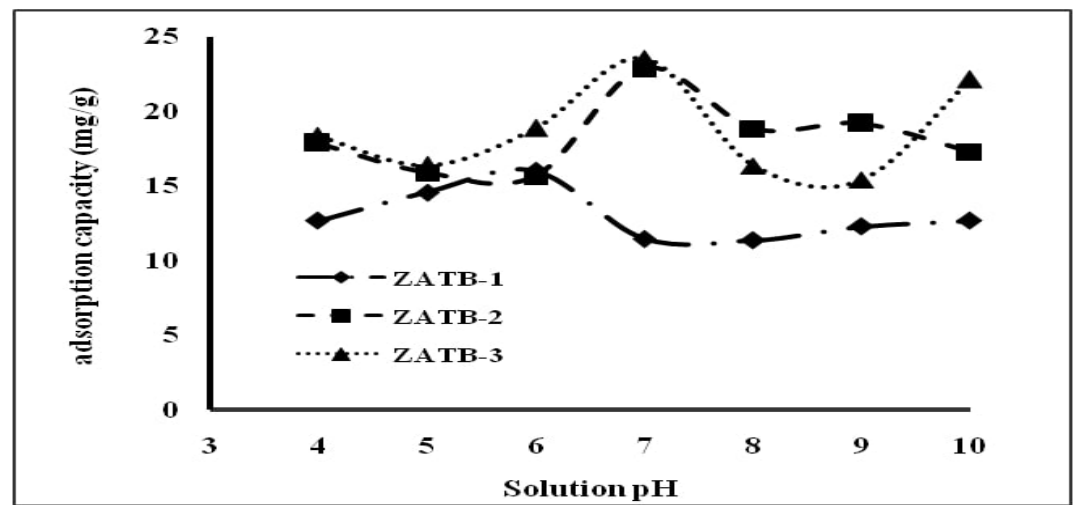

Fig.-4: Effect of Initial pH on the CR Adsorption on ZATB (Experimental Conditions: Adsorbent Dosage $=0.5$ $\mathrm{g} / \mathrm{L}$, Initial CR Concentration $=20 \mathrm{mg} / \mathrm{L}$, Contact Time $=60 \mathrm{~min}$, Solution Volume $=20 \mathrm{~mL}$ )

\section{Influence of Dosage on CR Adsorption}

Dosage of adsorbent determines the adsorbent capacity for a given initial dye concentration. Commonly, the dye removal increases with increasing adsorbent dosage, where the exchangeable number of sites on the adsorbent surface increases by increasing the adsorbent dosage ${ }^{31}$. Figure-5 displays that the CR adsorption increases as the dosage of modified zeolites increases.

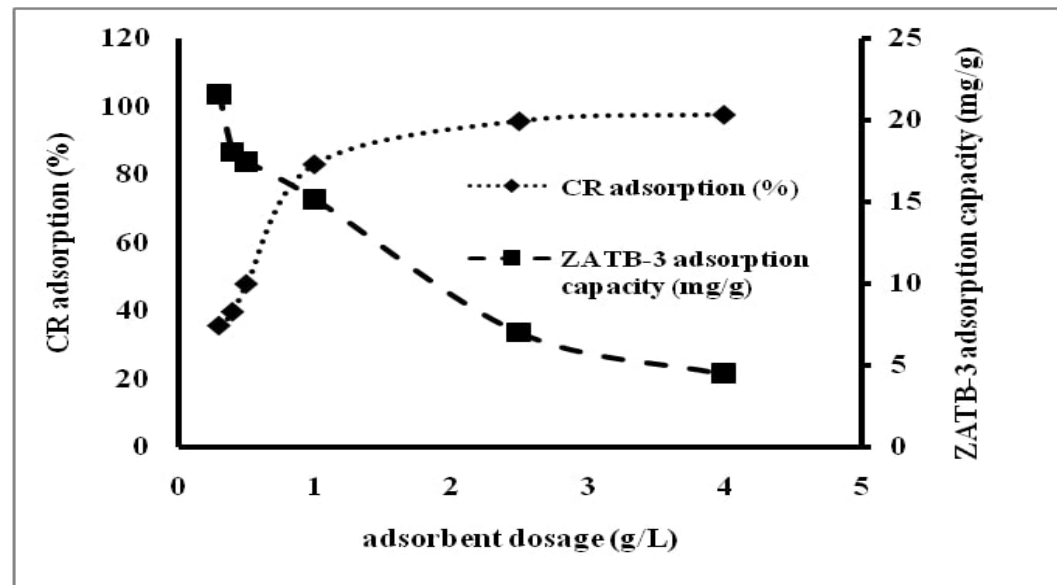

Fig.-5: Effect of Adsorbent Dosage on the Adsorption of CR and the Adsorption Capacity of ZATB-3 (Experimental Conditions: Solution Volume $=20 \mathrm{~mL}$, Initial CR Concentration $=20 \mathrm{mg} / \mathrm{L}$, Contact Time $=60 \mathrm{~min}$, $\mathrm{pH}=7.0)$

The percentage of $\mathrm{CR}$ adsorption increased from $35.48 \%$ to $97.52 \%$ with an increase in adsorbent dosage 0.3 to $4.0 \mathrm{~g} / \mathrm{L}$. At higher adsorbent dosage, the percentage of CR adsorption using surfactantmodified zeolites gradually increases. This probably due to the increasing amount of the zeolite increased the surface area and the number of vacant adsorption sites on zeolite ${ }^{33}$. On the contrary, the adsorption capacity of $\mathrm{CR}$ was decreased with an increase in adsorbent dosage ${ }^{29}$. This could be because the unsaturation of the ion-exchange sites of the zeolites occurred. In this study, the optimum dosage of 
RASĀYAN J. Chem.

Vol. 13 | No. 2 |845 - 853| April - June | 2020

adsorbent was taken as $1.0 \mathrm{~g} / \mathrm{L}$ for further experiments. Adsorption of CR dye is limited to the external surface of the surfactant-modified zeolite due to the molecular size of CR is too large than the pore size of ZATB. Based on the zeta potential analysis results, the surface of the surfactant-modified zeolites carried positive charges, and therefore the CR could be easily adsorbed via electrostatic attraction.

\section{Influence of Contact Time on CR Adsorption}

The effect of contact time on CR adsorption was examined at various adsorption durations $(15,20,30,45$, $60,70,80$ and $90 \mathrm{~min}$ ). The initial $\mathrm{pH}$ was set at 6 (ZATB-1) and 7 (ZATB-2 and ZATB-3). The experimental results were shown in Fig.-6. It is perceptible that the optimum contact time was fixed to be 20 min since the adsorption reached equilibrium after this time.

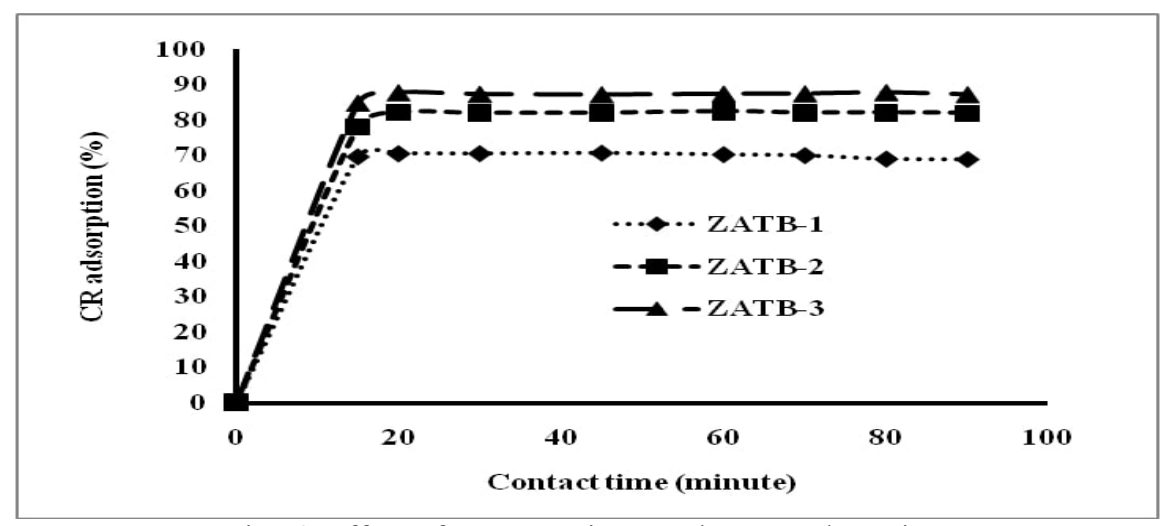

Fig.-6: Effect of Contact Time on the CR Adsorption

Commonly, the initial rate of adsorption efficiency increased rapidly, and then slower adsorption would follow as the available sorption sites are slowly decreased ${ }^{34}$. This behavior could be assigned to the quick employment of the most readily available sorption sites of the zeolites for adsorption during the initial stage. After the adsorption reached equilibrium, the remaining unoccupied surface sites are difficult to be occupied due to repulsive forces between dye molecules on the surface of the zeolite. Therefore, it is important to be able to investigate the rate of CR adsorption onto zeolite.

To investigate the kinetic parameters of CR onto surfactant-modified zeolites, the pseudo-first-order and pseudo-second order were tested to analyze the kinetic models, based on the kinetic model equations. The pseudo-first order kinetic model, suggested by Lagergreen, has been widely used to investigate the dye adsorption kinetics. The adsorption kinetics of dye that follows the pseudo-first order model is expressed as: ${ }^{35}$

$$
\frac{d q}{d t}=k_{1}\left(q_{e}-q\right)
$$

Where $\mathrm{q}$ is the amount of dye adsorbed $(\mathrm{mg} / \mathrm{g})$ at time $\mathrm{t}(\mathrm{min})$, qe is the amount of dye adsorbed $(\mathrm{mg} / \mathrm{g})$ at equilibrium time, and $\mathrm{k}_{1}$ represents the adsorption rate constant $\left(\mathrm{min}^{-1}\right)$.

The kinetics of the adsorption process were further studied in the pseudo-second order kinetic model suggested by Ho et al. ${ }^{36}$ which is represented as:

$$
\frac{d q}{d t}=k_{2}\left(q_{e}-q\right)^{2}
$$

The values of kinetic constants for CR adsorption onto zeolite are shown in Table-1.

By comparing the correlation coefficients $\mathrm{R}^{2}$ for all types of adsorbent in Table- 1 , the pseudo- first-order kinetic model is not suitable for modeling the CR adsorption on surfactant-modified zeolite. The results suggest that the higher $R^{2}$ values obtained with the pseudo-second order kinetic model $\left(R^{2}=0.999\right)$. This shows that the adsorption kinetics of CR adsorption on ZATB is better represented by the pseudo-second order model, implying that the mechanism of adsorption depends on the adsorbent, adsorbate, and the chemisorption mechanism may control the rate-limiting ste $\mathrm{p}^{22,29}$. The similar results for the CR adsorption have also been reported onto clay materials ${ }^{22}$, natural zeolites modified with N,N-dimetyl 
RASĀYAN J. Chem.

Vol. 13 | No. 2 |845 - 853| April - June | 2020

dehydroabietylamine oxide ${ }^{16}$, HDTMA surfactant-modified zeolite synthesized from fly ash ${ }^{33}$, polyhedral $\mathrm{Cu}_{2} \mathrm{O}$ nanoparticles ${ }^{37}$, and flower-shaped $\mathrm{ZnO}$ nanoparticles ${ }^{38}$.

Table-1: Kinetic Parameters for Adsorption of CR onto ZATB-1, ZATB-2, and ZATB-3

\begin{tabular}{c|c|c|c}
\hline & ZATB-1 & ZATB-2 & ZATB-3 \\
\hline \multicolumn{4}{|c|}{ Pseudo-first Order } \\
\hline $\mathrm{k}_{1}\left(\mathrm{~min}^{-1}\right)$ & 0.066 & 0.017 & 0.117 \\
\hline $\mathrm{R}^{2}$ & 0.920 & 0.564 & 0.708 \\
\hline $\mathrm{k}_{2}\left(\mathrm{~g} \mathrm{mg}^{-1} \mathrm{~min}^{-1}\right)$ & 0.330 & 0.223 & 0.305 \\
\hline $\mathrm{R}^{2}$ & 0.999 & 0.999 & 0.999 \\
\hline
\end{tabular}

\section{Adsorption Isotherms of CR}

In the present study, the equilibrium data were determined by Langmuir and Freundlich isotherm expression given by the Langmuir and Freundlich equations. Figure-7 shows that the amount of CR adsorbed (mg/g) increases with an increase in initial dye concentration (from 2 to $45 \mathrm{mg} / \mathrm{L}$ ). This is caused by increasing the concentration gradient driving force with the increase in initial dye concentration. The maximum adsorption capacity remains unaltered for the modification with $200 \%$ and $300 \%$ of ECEC, which indicates that the loaded BC had reached saturation, probably due to the formation of bilayer of $\mathrm{BC}$ on zeolite for these two modifications of adsorbents.

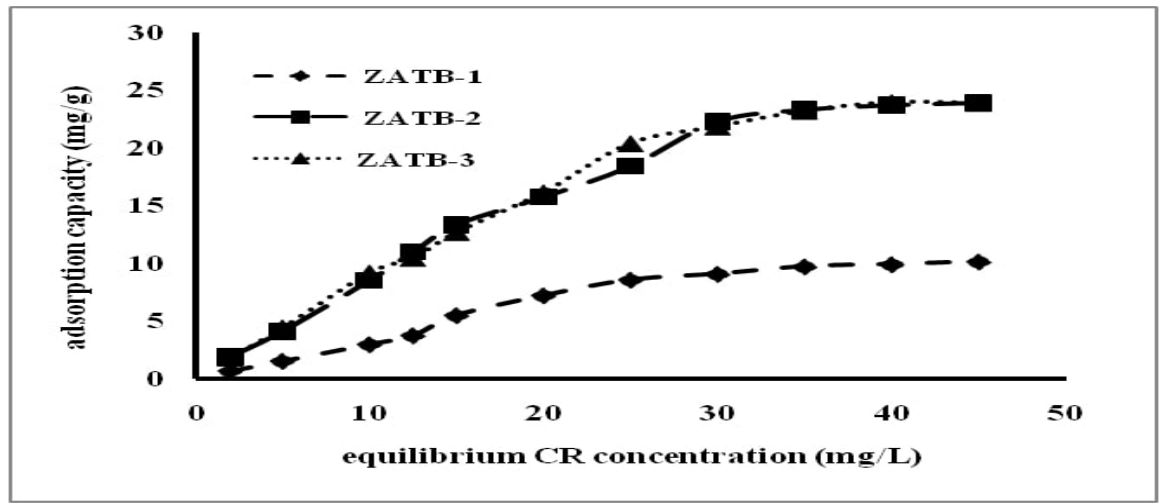

Fig.-7: CR Adsorption Isotherms onto ZATB (Experimental Conditions: Adsorbent Dosage $=1 \mathrm{~g} / \mathrm{L}$, Solution Volume $=20 \mathrm{~mL}, \mathrm{pH}=6$ (ZATB-1), $\mathrm{pH}=7$ (ZATB-2 and ZATB-3))

The application of adsorption isotherms available for analyzing the interaction between the adsorbate and the adsorbent ${ }^{39}$. The isotherm shapes give important information on the mechanism of adsorption, the affinities and surface properties of the adsorbent ${ }^{40}$. In the present investigation, Langmuir dan Freundlich models were used to represent the adsorption of CR dye on surfactant-modified zeolite. The values of isotherm constants are given in Table-2.

Table-2: Isotherm Parameters for CR Adsorption on the Surfactant-modified Zeolites

\begin{tabular}{c|c|c|c|c|c|c}
\hline \multirow{2}{*}{ adsorbent } & \multicolumn{3}{|c|}{ Langmuir model } & \multicolumn{3}{c}{ Freundlich model } \\
\cline { 2 - 7 } & $\mathrm{q}_{\mathrm{m}}$ & $\mathrm{k}_{\mathrm{L}}$ & $\mathrm{R}^{2}$ & $\mathrm{k}_{\mathrm{F}}$ & $1 / \mathrm{n}$ & $\mathrm{R}^{2}$ \\
\hline ZATB-1 & 10.42 & 2.34 & 0.994 & 7.75 & 0.116 & 0.854 \\
\hline ZATB-2 & 19.61 & 1.34 & 0.990 & 8.87 & 0.466 & 0.948 \\
\hline ZATB-3 & 25 & 2.5 & 0.999 & 15.64 & 0.22 & 0.915 \\
\hline
\end{tabular}

The Langmuir adsorption isotherm assumes that monolayer coverage of adsorbent and adsorption takes place at specific homogenous sites on the adsorbent $t^{41}$. The obtained correlation coefficient $\left(\mathrm{R}^{2}\right)$ of Langmuir isotherm was higher than the Freundlich model, indicating that the adsorption data were well described by the Langmuir isotherm model and supported the assumption that CR was homogeneously adsorbed onto zeolite surface ${ }^{38}$. Similar behavior has also been reported for CR adsorption onto natural zeolites modified with N,N-dimethyl dehydroabietylamine oxide ${ }^{16}$.

The measurements of zeta potential resulted in the positive charge of the surfactant-modified zeolite sample. It was observed the after modification surfactant $\mathrm{BC}$ formed a double layer on the number of 
RASĀYAN J. Chem.

Vol. 13 | No. 2 |845 - 853| April - June | 2020

active sites on the external zeolite surface ${ }^{33}$. The highest zeta potential was obtained for ZATB-3. The adsorption is controlled by electrostatic attraction of the dye anionic groups onto adsorbed cationic head groups of the $\mathrm{BC}$ molecules. A complete organic monolayer surface coverage by $\mathrm{BC}$ is expected to be obtained from zeolite modification with $100 \%$ of ECEC, meaning that in this case hydrogen bonding and hydrophobic interaction are recommended to be alternative mechanisms in CR adsorption by ZATB-1.

\section{CONCLUSION}

This study has shown that modification of zeolite using cationic surfactant benzalkonium chloride can be used as an effective adsorbent to remove congo red from aqueous solution. Conditions of solution $\mathrm{pH}$, adsorbent dosage, and contact time have been found to affect the adsorption of CR on ZATB. The amount of dye uptake increases with the increase of contact time and initial dye concentration. The CR is rapidly absorbed from the solution within 20 min of the contact time, and the process follows the pseudo-secondorder kinetic adsorption model. Moreover, the equilibrium data can be well fitted with the Langmuir isotherm equation. The CR adsorption on ZATB-3 (surfactant three times higher than the ECEC value) gives the largest result, suggesting that the higher bilayer of surfactant is probably formed on the zeolite surface to give positively charged surface.

\section{ACKNOWLEDGMENT}

This research was supported by LPDP scholarship (Grant Number: PRJ-4908 /LPDP.3/2016) for first author and the Department of Chemistry Gadjah Mada University for providing facilities to carry out the study.

\section{REFERENCES}

1. Sh. Sohrabnezhad and A. Pourahmad, Desalination, 256, 84(2010), DOI:10.1016/j.desal.2010.02.009

2. D. Karadag, E. Akgul, S. Tok, F. Erturk, M.A. Kaya and M. Turan, Journal of Chemical and Engineering Data, 52, 2436(2007), DOI:10.1021/je7003726

3. B. Abbad, A. Lounis and T. Djilali, International Journal of Materials and Metallurgical Engineering, 6(11), 1086(2012)

4. S. Çoruh, S. Elevli and G. Doğan, Global NEST Journal, 19(2), 336(2017), DOI:10.30955/gnj.002128

5. R. Ansari, B. Seyghali, A. Mohammad-khah and M.A. Zanjanchi, Journal of Surfactants and Detergents, 15, 557(2012), DOI:10.1007/s11743-012-1334-3

6. W.J. Fendi and J.A. Naser, Oriental Journal of Chemistry, 34(6), 2884(2018), DOI: $10.13005 / \mathrm{ojc} / 340628$

7. M. Jeeva and W.Y. Wan Zuhairi, Asian Journal of Chemistry, 30(11), 2383(2018), DOI:10.14233/ajchem.2018.21309

8. D.A. Fungaro, M. Bruno and L.C. Grosche, Desalination and Water Treatment, 2, 231(2009), DOI: $10.5004 /$ dwt.2009.305

9. A. Sayal, V.K. Bulasara and S. Barman, Chemical and Process Engineering Research, 2, 54(2012)

10. M. Canli, Y. Abali and S.U. Bayca, Physicochemical Problems of Mineral Processing, 49(2), 481(2013), DOI:10.5277/ppmp130210

11. S. Wang and Y. Peng, Chemical Engineering Journal, 156(1), 11(2010), DOI: $10.1016 / j . c e j .2009 .10 .029$

12. M. Rožić and S. Miljanić, Journal of Hazardous Materials, 185, 423(2011), DOI: 10.1016/j.jhazmat.2010.09.050

13. D.A. Fungaro and C.P. Magdalena, Environment and Ecology Research, 2(2), 97(2014), DOI: 10.13189/eer.2014.020206

14. X. Jin, M. Jiang, X. Shan, Z. Pei and Z. Chen, Journal of Colloid and Interface Science, 328, 243(2008), DOI:10.1016/j.jcis.2008.08.066

15. J. Lemić, M. Tomašević-Čnović, M. Adamović, D. Kovačević and S. Milićević, Microporous and Mesoporous Materials, 105, 317(2007), DOI:10.1016/j.micromeso.2007.04.014

16. S. Liu, Y. Ding, P. Li, K. Diao, X. Tan, F. Lei, Y. Zhan, Q. Li, B. Huang and Z. Huang, Chemical Engineering Journal, 248, 135(2014), DOI:10.1016/j.cej.2014.03.026

17. W. Cheng, N. Li, Y. Pan and L. Jin, Modern Applied Science, 10(5), 67(2016), 852 
RASĀYAN J. Chem.

Vol. 13 | No. 2 |845 - 853| April - June | 2020

DOI: $10.5539 / \mathrm{mas} . v 10 \mathrm{n} 5 \mathrm{p} 67$

18. S.R. Taffarel and J. Rubio, Minerals Engineering, 23(10), 771(2010), DOI: $10.1016 /$ j.mineng.2010.05.018

19. T.C.R. Bertolini, J.D.C. Izidoro, R.R. Alĉantara, L.C. Grosche and D.A. Fungaro, Acta Velit, 1(4), 78(2015)

20. S. Syafalni, S.R.B. Sing and M.H. Zawawi, World Applied Sciences Journal, 32(5), 818(2014), DOI: 10.5829/idosi.wasj.2014.32.05.1015

21. R. Leyva-Ramos, A. Jacobo-Azuara, P.E. Diaz-Flores, R.M. Guerrero-Coronado, J. Mendoza-Barron and M.S. Berber-Mendoza, Colloids and Surfaces A: Physicochemical and Engineering Aspects, 330, 35(2008), DOI:10.1016/j.colsurfa.2008.07.025

22. V. Vimonses, S. Lei, B. Jin, C.W.K. Chow and C. Saint, Chemical Engineering Journal, 148, 354(2009), DOI:10.1016/j.cej.2008.09.009

23. D.W. Astuti, Mudasir and N.H. Aprilita, Journal of Physics: Conference Series, 1156 (2019), DOI: $10.1088 / 1742-6596 / 1156 / 1 / 012002$

24. D.W. Ming and J.B. Dixon, Clays and Clay Minerals, 35(6), 463(1987), DOI: 10.1346/CCMN.1987.0350607

25. S. Jevtić, S. Grujić, J. Hrenović and N. Rajić, Microporous and Mesoporous Materials, 159, 30(2012), DOI:10.1016/j.micromeso.2012.04.014

26. T. Farías, L.C. de Ménorval, J. Zajac and A. Rivera, Journal of Colloid and Interface Science, 363(2), 465(2011), DOI:10.1016/j.jcis.2011.07.067

27. D. Krajišnik, A. Daković, A. Malenović, M. Milojević, V. Dondur and J. Milić, In Proceedings of the 3rd Croatian-Slovenian Symposium on Zeolites, Trogir, Croatia, pp. 23-26 (2010)

28. C.D.R. Oliveira and J. Rubio, Materials and Research, 10(4), 407(2007)

29. Y. Sun, J. Lin and Y. Zhan, Separation Science and Technology, 48, 2036(2013), DOI: $10.1080 / 01496395.2013 .790448$

30. H. Revathi, A. Xavier, M.D. Kumar, T. Saranya, A. Kaviyarasu, and T. Murugan, Rasayan Journal of Chemistry, 12(2), 719(2019), DOI: 10.31788/RJC.2019.1225094

31. T.W. Seow and C.K. Lim, International Journal of Applied Engineering Research, 11(4), 2675(2016), DOI:10.1007/s11356-015-5880-x

32. M.A.M. Salleh, D.K. Mahmoud, W.A.W.A. Karim and A. Idris, Desalination, 280, 1(2011), DOI: 10.1016/j.desal.2011.07.019

33. Jumaeri, S.J. Santosa and Sutarno, Defect and Diffusion Forum, 382, 307(2018), DOI: $10.4028 /$ www.scientific.net/ddf.382.307

34. A. Basker, P.S. Syed Shabudeen, S. Daniel, and P.V. Kumar, Rasayan Journal of Chemistry, 7(1), $1(2014)$

35. Y.S. Ho and G. McKay, The Canadian Journal of Chemical Engineering, 76, 822(1998), DOI: $10.1002 /$ cjce. 5450760419

36. Y.S. Ho, D.A.J. Wase and C.F. Forster, Environmental Technology, 17, 71(1996), DOI: $10.1080 / 09593331708616362$

37. J. Shu, Z. Wang, Y. Huang, N. Huang, C. Ren and W. Zhang, Journal of Alloys and Compounds, 633, 338(2015), DOI:10.1016/j.jallcom.2015.02.048

38. N. Kataria and V.K. Garg, Journal of Environmental Chemical Engineering, 5, 5420(2017), DOI: $10.1016 /$ j.jece.2017.10.035

39. A.R. Utami, S. Sugiarti, and P. Sugita, Rasayan Journal of Chemistry, 12(2), 650(2019), DOI: 10.31788/RJC.2019.1222056

40. Y.A.B. Neolaka, E.B.S. Kalla, G.A. Malelak, and N.K. Rukman. Rasayan Journal of Chemistry, 11(2), 494(2018), DOI: 10.31788/RJC.2018.1121994

41. Y.A.B. Neolaka, E.B.S. Kalla, G. Supriyanto, N. Nyoman, and T. Puspaningsih, Rasayan Journal of Chemistry, 10(2), 606(2017), DOI:10.7324/RJC.2017.1021710

[RJC-5537/2019] 